http://dx.doi.org/10.5007/1981-1322.2014v9nespp21

\title{
Objetivos e resultados da pesquisa em Modelagem Matemática na Educação Matemática brasileira: o caso de uma categoria
}

\author{
Objectives and results of research in Mathematical Modeling in Brazilian Mathematics \\ Education: the case of a category
}

\author{
Dionísio Burak ${ }^{1}$ \\ dioburak@yahoo.com.br \\ Célia Finck Brandt ${ }^{2}$ \\ brandt@,bighost.com.br \\ Vantielen da Silva Silva ${ }^{3}$ \\ vantisilva@gmail.com
}

\begin{abstract}
Resumo
Neste artigo apresentamos considerações em relação aos dados que envolvem a categoria: Objetivos que buscam relacionar a Modelagem Matemática com outras teorias, tendências ou tecnologias e seus respectivos resultados revelados nos trabalhos apresentados e constantes nos anais da VI Conferência Nacional de Modelagem em Educação Matemática - VI CNMEM. A questão de fundo é: O que revelam os objetivos e os resultados dos trabalhos publicados no âmbito da VI CNMEM? A natureza da investigação é predominantemente qualitativa e a análise dos dados se pautou nas orientações de Bardin (2009) para a análise de conteúdo. Foram analisados quinze (15) trabalhos submetidos ao evento, com o auxílio do software Atlas ti. Alguns resultados mostram o avanço na busca de associar a Modelagem com outras tendências da Educação Matemática, mas também ainda uma pequena contribuição em relação à consolidação do campo da Modelagem na Educação Matemática.
\end{abstract}

Palavras-chave: Modelagem Matemática. Educação Matemática. Tendências. Pesquisa meta-analítica.

\begin{abstract}
This article presents considerations regarding the data involving the category: Objectives that seek association of Modeling Mathematics with other theories, trends or technologies and their results presented and disclosed in constant work in the annals of the Sixth National Conference on Mathematical Modeling in Education VICNMEM . The question to be answered is: How if show the objectives and results of published works within the VI CNMEM? The nature of research is predominantly qualitative and data analysis was based under the guidelines of Bardin (2009) for content analysis. Were analised 15 papers submitted to the event, with the aid of

\footnotetext{
${ }^{1}$ Doutor em Educação pela Universidade Estadual de Campinas - UNICAMP. Professor do Programa de PósGraduação em Educação da Universidade Estadual de Ponta Grossa - UEPG e do Mestrado profissional em Ensino de Ciências Naturais e Matemática da Universidade Estadual do Centro-Oeste - UNICENTRO, Guarapuava.

${ }^{2}$ Doutora em Educação Científica e Tecnológica pela Universidade Federal de Santa Catarina - UFSC. Professora do Programa de Pós-Graduação em Educação da Universidade Estadual de Ponta Grossa - UEPG.

${ }^{3}$ Mestra em Educação pela Universidade Estadual do Oeste do Paraná - UNIOESTE. Professora colaboradora no curso de Pedagogia da Universidade Estadual do Centro-Oeste do Paraná - UNICENTRO, Guarapuava.
} 
Atlas ti software. The results show some progress in seeking associate modeling with other trends in mathematics education, but a small contribution in the consolidation of Mathematics Modeling in the Mathematic Education.

Keywords: Mathematics Modeling. Mathematics Education. Trends. Meta-analytic research.

\section{Considerações iniciais}

A Modelagem Matemática tem, ao longo de quase três décadas, se constituído como uma promissora maneira de ensinar matemática, com vistas à aprendizagem, em todos os níveis e modalidades da educação. Assim, o campo da Modelagem na Educação Matemática tem apresentado uma considerável expansão quantitativa diante de outros campos da Educação Matemática. Tal perspectiva se sustenta por apresentar eventos específicos que tratam sobre a Modelagem em âmbito regional, estadual, nacional ou internacional. Entre os vários eventos na área, destaca-se o Simpósio Internacional de Pesquisa em Educação Matemática - SIPEM, no qual várias áreas da Educação Matemática se fazem presentes, com seus respectivos Grupos de Trabalhos - GTs - e, dentre elas, a Modelagem Matemática, por meio do GT-10 é considerado relevante por reunir a comunidade nacional e internacional de pesquisa sobre Modelagem Matemática.

Este GT-10, da Modelagem, estabelece um espaço de discussão da produção da pesquisa e das práticas da Modelagem Matemática desenvolvidas nos grupos de pesquisas estabelecidos nas instituições brasileiras e, vem sendo realizados, no âmbito do SIPEM, com edições trienais. A sua última edição aconteceu em 2012, em Petrópolis - RJ. Ao final de cada evento é apresentado um relatório que, entre outros assuntos, levanta questões e pontos merecedores de discussão e reflexão entre os pesquisadores. $\mathrm{O}$ resultado dessas discussões e reflexões sobre a pesquisa, na maioria das vezes, constitui-se orientador da prática em Modelagem Matemática em âmbito escolar e também em aparato para pensar e refletir a pesquisa do próprio campo.

O último relatório elaborado pelos professores pesquisadores em Modelagem Matemática, Almeida, Vertuam e Klüber (2012), conforme contido no boletim temático no 19 da Sociedade Brasileira de Educação Matemática, de dezembro de 2012, aponta a pesquisa como ponto polêmico em relação às teorias envolvidas nas pesquisas e à necessidade de estudos que busquem metacompreensão sobre o campo da Modelagem. Também se discutiu a necessidade de mais estudos sobre as bases epistemológicas que, de forma direta e indireta, influenciam as práticas de modelagem nas escolas. O relatório continua assinalando a necessidade de investigações sobre essa mesma produção, isto é, abre, em seu âmago, investigações sobre a própria pesquisa que está sendo realizada por esta comunidade.

Nesse sentido, pesquisar a própria pesquisa é uma ação que mostra a disposição de a comunidade conhecer e refletir sobre aquilo que produz, convencida de sua responsabilidade em relação ao campo e também sabedora que ao não conhecer a qualidade e profundidade daquilo que se produz, pode ocasionar riscos à consolidação do campo da Modelagem na perspectiva da Educação Matemática. 
A solicitação de metaestudos é também uma demanda em âmbito internacional e, em seus estudos, Niss (2001) faz emergir três questões atinentes às pesquisas sobre o ensino e a aprendizagem de aplicações e Modelagem Matemática, a saber: 1) O que sabemos sobre essas pesquisas; 2) o que não sabemos sobre elas e, 3) as demandas gerais da pesquisa em Modelagem Matemática. Nesta última questão, o autor insta, entre outras, aquela que promove a realização de estudos meta-analíticos em aplicações de Modelagem no âmbito da Educação Matemática.

Como decorrência dessa solicitação, ou mesmo pela necessidade sentida na perspectiva de avanços no campo, alguns pesquisadores brasileiros, desde a metade da década passada realizam trabalhos, dentre os quais podemos citar Almeida (2006), Barbosa (2007), Araújo (2009) e mais recentemente Bicudo e Klüber (2011), buscando tratar dessa problemática em âmbito nacional, cujos resultados podem contribuir para novos estudos.

Desse modo, nesse contexto, desenvolvemos um projeto ${ }^{4}$ denominado Modelagem Matemática no Brasil: na perspectiva da meta-compreensão, cujo foco centra-se na busca por uma metacompreensão da Modelagem, especificamente para explicitar sentidos e significados atribuídos a tal prática tanto na área específica da Educação Matemática como em termos específicos do ensino de Matemática na Educação Básica.

Configura-se, pois como objeto de pesquisa, a Modelagem Matemática na Educação Matemática compreendendo a investigação das abordagens postas e tratadas nos trabalhos produzidos e publicados: 1) em eventos científicos e pedagógicos de caráter nacional e internacional, realizados no Brasil, relativos à temática / prática educativa entre 2005 e 2009, 2) em artigos de revistas e periódicos, com qualis igual ou superior a B3, que acolheram pontos de vista sobre Modelagem Matemática no mesmo período, envolvendo pesquisadores e instituições universitárias das várias regiões brasileiras. Entre os eventos científicos e pedagógicos foram analisados os trabalhos dos anais da IV, V e VI Conferência Nacional de Modelagem em Educação Matemática - CNMEM, realizados respectivamente nos anos de 2005, 2007 e 2009; e do IX e X Encontro Nacional de Educação Matemática - ENEM; realizados em 2007 e 2010.

No presente artigo, como parte dos resultados deste projeto meta-analítico sobre a Modelagem Matemática na Educação Matemática Brasileira, focamos especificamente a questão: $\mathrm{O}$ que revelam os objetivos, que constituem a categoria - Objetivos que buscam associar a Modelagem Matemática com teorias, tendências e tecnologias e, seus respectivos resultados, nos trabalhos publicados no âmbito do VI CNMEM?

\section{Procedimentos gerais}

\footnotetext{
${ }^{4}$ Projeto desenvolvido pelo Grupo de Pesquisa e Ensino em Educação Matemática, do Departamento de Matemática da Unicentro, Guarapuava - PR, financiado pela Fundação Araucária, órgão de fomento de pesquisas do estado do Paraná. Sob a coordenação do Prof. Dr. Dionísio Burak e dos professores: Dr. ${ }^{a}$ Célia Finck Brandt, Dr. Tiago Emanuel Klüber e Me. Carlos Roberto Ferreira.
} 
Neste trabalho, lançamos olhares mais atentos aos elementos já mencionados: objetivos pertencentes à categoria - Objetivos que buscam associar a Modelagem Matemática com teorias, tendências e tecnologias - e os respectivos resultados, constantes dos trabalhos apresentados na VI CNMEM. Assim, estamos interessados na análise dos conteúdos manifestos pelos dois descritores e também no latente, ou seja, naquilo que sustenta o discurso manifesto, sem focar os autores, mas o contexto. Na análise geral, foram tomados 31 artigos constantes dos anais do VI CNMEM, inseridos na categoria de comunicações científicas, pois se considera que, nesta modalidade, deva haver maior rigor na elaboração dos trabalhos. No entanto, relativizamos essa afirmação, por sabermos que o evento é misto, envolvendo pesquisadores iniciantes e experientes.

A metodologia de análise dos dados seguiu as orientações propostas na análise de conteúdo, tal opção, conforme Bardin (2009, p.21) "dá-se pela busca de se compreender para além dos seus significados, imediatos parecendo útil, a proposição à análise de conteúdo". Para Bardin (2009), essa fase de tratamento dos dados se subdivide, basicamente, em três etapas: 1) préanálise, 2) descrição analítica e 3) interpretação inferencial.

A pré-análise consistiu na leitura prévia e organização dos materiais. Na descrição analítica, etapa de tratamento das informações e análise de significado, foi efetuada as codificações.

A codificação, segundo Holsti (1969 apud BARDIN, 2009, p.129), “[...] é o processo pelo qual os dados em bruto são transformados sistematicamente e agregados em unidades, as quais permitem uma descrição exata das características pertinentes do conteúdo". Por meio dessa codificação foram instituídos descritores que trataram mais especificamente dos objetivos e dos resultados no material apresentado durante a realização da VI CNMEM. Os textos foram revisitados caracterizando, ainda, a etapa da pré-análise. Os dados foram organizados com auxílio do software Atlas ti.

A interpretação inferencial e interpretação mais ampla são destinadas ao tratamento dos resultados; ocorre nela à condensação e o destaque das informações para análise, culminando nas interpretações inferenciais; é o momento da intuição, da análise reflexiva e crítica (Bardin, 2009).

O software Atlas ti foi idealizado exclusivamente para a análise de dados qualitativos em grande quantidade, o que se tornou conveniente ao nosso trabalho. De acordo com o estudo realizado por Walter e Bach (2009), a primeira edição comercial do software foi lançada em 1993 na Bélgica. Desde então passou a ser utilizado em diferentes áreas do conhecimento, primeiramente por adeptos da grounded theory (teoria fundamentada ou enraizada nos dados). Recentemente vem sendo empregado por pesquisadores que se valem da análise de conteúdo, em distintas vertentes ${ }^{5}$. Daí a possibilidade de sua utilização nesta pesquisa.

\footnotetext{
${ }^{5}$ Klüber (2012) utilizou em sua tese adaptando o software segundo a visão Fenomenológica de pesquisa. KLÜBER, T.E. Uma metacompreensão da Modelagem Matemática na Educação Matemática. 2012. 396 f. Tese (Doutorado em Educação Científica e Tecnológica) - Centro de Ciências Físicas e Matemática, Universidade Federal de Santa Catarina, Florianópolis, 2012.
} 
A análise de conteúdo propriamente dita emergiu a partir dos estudos realizados pelo grupo. Maiores detalhes podem ser encontrados nos $\operatorname{artigos}^{6}$ já publicados em relação ao projeto mencionado (BURAK et al, 2012; KLÜBER, BURAK, 2012a).

Figura 1: Categoria - Objetivos que buscam associar MM e outras teorias, tendências ou tecnologias, por meio de seus códigos.

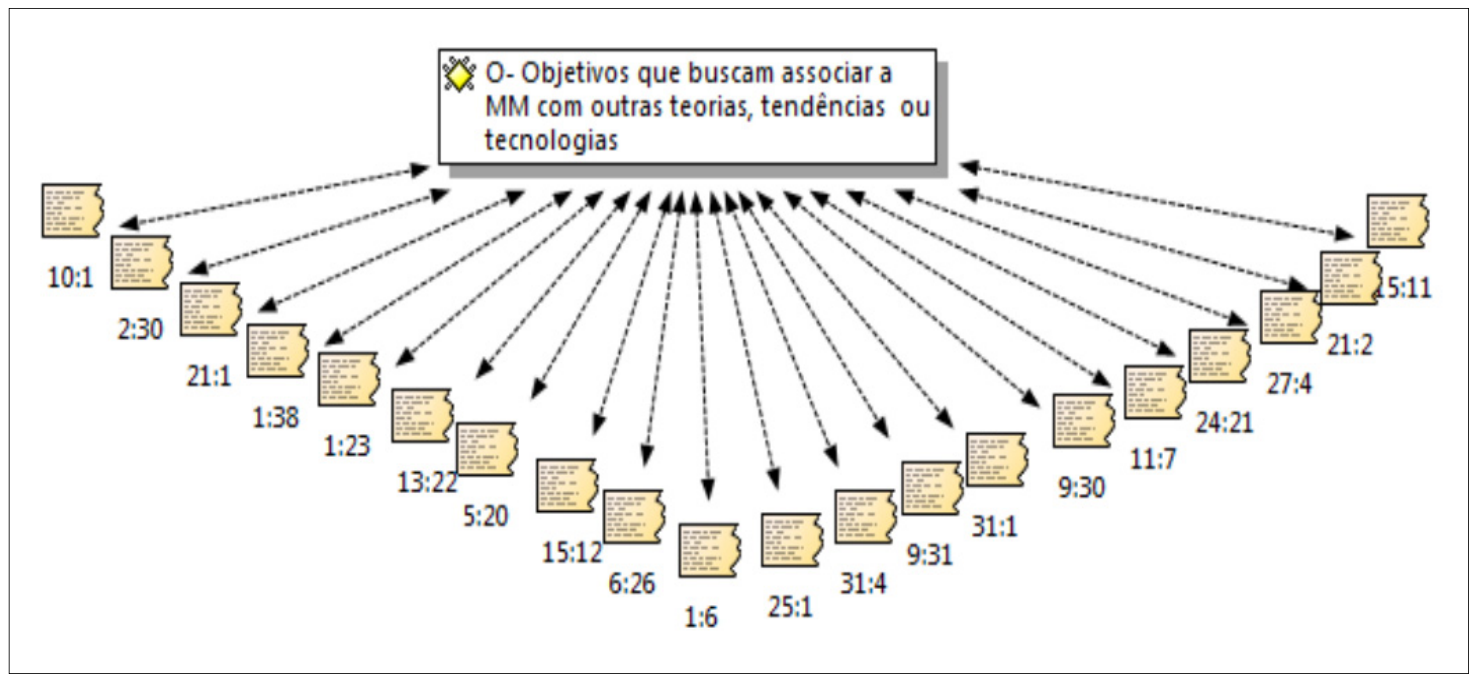

Fonte: Os autores

\section{Procedimentos de análise}

Como já esclarecemos, o foco deste trabalho se concentrou na análise dos objetivos e resultados contidos nos 31 artigos, constantes dos anais, apresentados durante a realização do VI Conferência Nacional de Modelagem em Educação Matemática. Incluiu ao menos duas leituras de cada artigo e codificação primária, ou seja, uma análise textual para destacar os elementos buscados no texto.

Efetuadas todas as codificações, passamos à segunda etapa que consistiu em interrogar os significados de todos os objetivos e resultados explicitados nas comunicações científicas analisadas. Optamos por essa recodificação por entender que ela expressa um rigor acerca do qualitativo, quando se busca uma compreensão refletida sobre o codificado. Em suma, efetuamos as inferências que conduziram as categorizações que passamos a apresentar.

Além disso, avaliamos que ao transformar a citação em código, como apresentado na figura 1 , torna-se mais fácil e menos poluído, visualmente, o trabalho com a categorização.

\footnotetext{
${ }^{6}$ BURAK, D. et al. Sobre os objetivos de pesquisa concernentes à investigação em modelagem matemática na educação matemática. In: SEMINÁRIO INTERNACIONAL DE PESQUISA EM EDUCAÇÃO MATEMÁTICA, 5., 2012, Petrópolis. Anais... Petrópolis: SIPEM, 2012, p.1-18.

KLÜBER, T. E.; BURAK, D. Sobre os objetivos, objetos e problemas da pesquisa brasileira em Modelagem Matemática na Educação Matemática. Revista Práxis Educativa, v. 7, n. 2, p. 467-488, jul/dez 2012b.
} 
Para a categorização, questionamos: qual o tema mais abrangente, além de particularidades, que se mostram a partir dos códigos? A partir daí foi possível chegar às seguintes categorias, que são autoexplicativas e que, estão apresentadas no quadro 1.

\begin{tabular}{|c|c|c|}
\hline Citações $^{7}$ & Núcleo de ideias relacionadas & Categoria \\
\hline $\begin{array}{lr}13: 22 ; 10: 1 ; \quad 24: 21 \\
21: 12 ; 1: 38 ; \quad 2: 30 \\
15: 12 ; 11: 7 ; 9: 30 ; 31: 1 ; \\
21: 1 ; 6: 26 ; 27: 4 ; 31: 4 \\
5: 20 ; 15: 11 ; 25: 1 ; 1.6 \\
1: 23 ; 9: 31\end{array}$ & $\begin{array}{l}\text { Objetivos que buscam estabelecer relações da } \\
\text { Modelagem Matemática com outras teorias, } \\
\text { tendências em Educação Matemática e com a } \\
\text { tecnologia. }\end{array}$ & $\begin{array}{l}\text { Objetivos que buscam } \\
\text { relacionar a Modelagem } \\
\text { Matemática a outras } \\
\text { teorias, tendências ou } \\
\text { tecnologias. }\end{array}$ \\
\hline $29: 14 ; 29: 9 ; 18: 4 ; 18: 8$ & $\begin{array}{l}\text { Objetivos que buscam conhecer os diálogos } \\
\text { que ocorrem no ambiente de Modelagem } \\
\text { Matemática, compreensão das formas de } \\
\text { abordagem de uma situação matemática e os } \\
\text { discursos de outras áreas das Ciências e o } \\
\text { discurso matemático. }\end{array}$ & $\begin{array}{l}\text { Objetivos que buscam } \\
\text { estudar os diálogos e } \\
\text { interações na Modelagem } \\
\text { Matemática. }\end{array}$ \\
\hline $26: 12 ; 19: 9 ; 1: 22$ & $\begin{array}{l}\text { Objetivos que visam o desenvolvimento da } \\
\text { Modelagem em uma disciplina, ou à } \\
\text { compreensão do comportamento das soluções } \\
\text { de um modelo matemático }\end{array}$ & $\begin{array}{l}\text { Objetivos que evidenciam } \\
\text { a Modelagem Matemática } \\
\text { como Matemática Aplicada }\end{array}$ \\
\hline $\begin{array}{l}30: 6 ; 1: 6 ; 19: 1 ; 17: 39 \\
31: 2 ; 16: 2 ; 19: 15\end{array}$ & $\begin{array}{l}\text { Objetivos que visam mapear programas } \\
\text { curriculares de MM na formação de } \\
\text { professores, e em contextos específicos } \\
\text { objetivos que visam explorar a característica } \\
\text { da manufatura de ornamento do povo de Arica } \\
\text { e composições musicais de Bach }\end{array}$ & $\begin{array}{l}\text { Objetivos que sugerem } \\
\text { formas de utilização da } \\
\text { Modelagem Matemática } \\
\text { nos diversos níveis de } \\
\text { ensino e nas artes. }\end{array}$ \\
\hline $30: 20 ; 9: 31 ; 28: 10$ & $\begin{array}{l}\text { Objetivos que se voltam para a identificação } \\
\text { de diferentes concepções de Modelagem na } \\
\text { formação inicial de educadores e se diferentes } \\
\text { denominações levam à diferentes ações } \\
\text { educativas }\end{array}$ & $\begin{array}{l}\text { Objetivos que } \quad \text { visam } \\
\text { relacionar ações distintas } \\
\text { às diferentes concepções de } \\
\text { Modelagem Matemática }\end{array}$ \\
\hline $1: 22$ & $\begin{array}{l}\text { Objetivos que se voltam para a compreensão } \\
\text { do comportamento das soluções matemáticas } \\
\text { de um modelo matemático }\end{array}$ & $\begin{array}{lrr}\text { Objetivos } & \text { que } & \text { visam } \\
\text { compreender } & \text { situações } \\
\text { matemáticas } & \text { em } \text { um } \\
\text { modelo } & & \end{array}$ \\
\hline
\end{tabular}

Fonte: Os autores

A figura mostra as categorias relativas aos objetivos, as quais foram constituídas a partir das unidades de conteúdos extraídas de cada um dos 31 artigos pertencentes ao VI CNMEM: 1) objetivos que buscam relacionar $\mathrm{MM}^{8}$ a outras teorias, tendências ou tecnologias; 2) objetivos que buscam estudar diálogos e interações em MM; 3) objetivos que evidenciam a MM como Matemática Aplicada; 4) objetivos que sugerem formas de utilização da MM nos diversos níveis de ensino e nas artes; 5) objetivos que visam relacionar ações distintas às diferentes concepções de MM; 6) objetivos que visam compreender as situações matemáticas em um modelo em MM.

\footnotetext{
${ }^{7} \mathrm{O}$ código n:m é utilizado pelo software no qual n significa o número do artigo analisado, denominado de documento primário Pn (entre 1 e 31) e m o número do objetivo dentre os objetivos selecionados nos 31 artigos analisados (de $1 \mathrm{a} \mathrm{m})$.

${ }^{8}$ Utilizamos MM para representar Modelagem Matemática.
} 
Optamos, neste trabalho, para permitir uma melhor explicitação e análise, concentrar nossas análises e interpretações em um uma única categoria designada por: Objetivos que buscam relacionar a Modelagem Matemática com outras teorias, tendências ou tecnologias relacionando-os com seus respectivos resultados.

Para tanto, apresentamos no quadro 2, a síntese dos códigos das citações concernentes à categoria: Objetivos que buscam relacionar a Modelagem Matemática com outras teorias, tendências ou tecnologias e respectivos resultados.

Quadro 2: Síntese dos códigos e citações

\begin{tabular}{|l|l|l|}
\hline Artigo & Citação-Objetivo & Citação - Resultados \\
\hline P1 & $1: 6 ; 1: 23 ; 1: 38$ & $1: 27 ; 1: 29 ; 1: 309$ \\
\hline P2 & $2: 30$ & $2: 19 ; 2: 20 ; 2: 21 ; 2: 22 ; 2: 23 ; 2: 24 ; 2: 25: 2: 26 ; 2: 27 ; 2: 28 ; 2: 29$ \\
\hline P5 & $5: 20$ & $5: 18 ; 5: 19$ \\
\hline P6 & & $6: 21 ; 6: 22 ; 6: 23 ; 6: 24 ; 6: 25$ \\
\hline P9 & $9: 30 ; 9: 31$ & $9: 21 ; 9: 22 ; 9: 23 ; 9: 24 ; 9: 25 ; 9: 26 ; 9: 27 ; 9: 28 ; 9: 29$ \\
\hline P10 & $10: 1 ;$ & $10: 19 ; 10: 20 ; 10: 21 ; 10: 22$ \\
\hline P11 & $11: 6 ; 11: 7$ & $11: 17 ; 11: 18 ; 11: 19 ; 11: 20 ; 11: 21 ; 11: 22 ; 11: 23 ; 11: 24 ; 11: 25:$ \\
& & $11: 26 ; 11: 27 ; 11: 28$ \\
\hline P13 & $13: 22 ; 13: 23$ & $13: 12 ; 13: 13 ; 13: 14 ; 13: 15 ; 13: 16 ; 13: 17 ; 13: 18$ \\
\hline P14 & ---------- & $14: 3 ; 14: 4 ; 14: 8$ \\
\hline P15 & $15: 11 ; 15: 12$ & $15: 31 ; 15: 32 ; 15: 33 ; 15: 45 ; 15: 47 ; 15: 49 ; 15: 52 ; 15: 53$ \\
\hline P21 & $21: 1 ; 21: 2$ & $21: 34 ; 21: 35 ; 21: 36 ; 21: 37 ; 21: 38 ; 21: 39 ; 21: 40 ; 21: 41 ; 21: 42 ;$ \\
& & $21: 43 ; 21: 44 ;$ \\
\hline P24 & $24: 21$ & $24: 14 ; 24: 15 ; 24: 16 ; 24: 17 ; 24: 18: 24: 19 ; 24: 20$ \\
\hline P25 & $25: 1$ & $25: 13 ; 25: 14 ; 25: 15$ \\
\hline P27 & $27: 4$ & $27: 2 ; 27: 3 ; 27: 5$ \\
\hline P31 & $31: 1 ; 31: 2 ; 31: 4$ & $31: 3 ; 31: 19 ; 31: 20 ; 31: 21 ; 31: 22 ; 31: 25 ;$ \\
\hline
\end{tabular}

Fonte: Os autores

O quadro 2 apresenta três colunas: a primeira permite identificar o documento primário, portanto, o artigo em que a citação foi destacada; a segunda coluna apresenta os códigos dos artigos que envolvem a categoria em análise; e a terceira coluna apresenta os respectivos resultados destacados em de cada um dos respectivos artigos.

\section{Análise e interpretação dos resultados}

A categoria em estudo indica que os trabalhos analisados intencionaram constituir relações da Modelagem Matemática com outras teorias, tendências ou tecnologias em evidência na Educação Matemática. Entre elas destacam-se: Investigação Matemática, Práticas Colaborativas, Prática Educativa e Ambiente de Aprendizagem, Resolução de Problemas, Educação a Distância, Jogos Computacionais, Mídias Educacionais, Educação Estatística, Perspectiva Sócio-Critica, Teoria da Aprendizagem Significativa, Registros de Representação Semiótica, Prática Colaborativa e TICs.

\footnotetext{
${ }^{9} \mathrm{O}$ código n:m utilizado pelo software já foi explicado em nota de rodapé anterior.
} 
Essas ações mostram um momento importante para a Comunidade de Modelagem Matemática, em que se faz uma tentativa de superação de práticas ad hoc em Modelagem, isto é, apenas desenvolvendo atividades de modelagem, para certificar-se da eficácia ou não de uma das concepções existentes ou de uma teoria em estudo. A relação que se busca estabelecer com outras teorias, tendências ou com as tecnologias presentes da Educação Matemática tem propiciado a abertura a alguns avanços no campo da Modelagem Matemática voltado ao ensino da matemática, com o horizonte de estabelecer relações mais consistentes entre a teoria e a prática.

Os resultados relativos aos objetivos propostos que se constituíram no foco dos trabalhos apresentados no evento, estão representados por seus códigos no quadro 2, e revelam, também, mínimos avanços no sentido de congruência entre os objetivos, significando o que se almeja, e os resultados que encontraram do desenvolvimento da investigação realizada. Assim, a análise e interpretação consideram, em algum sentido, essa perspectiva de avanços. Para fundamentar as análises e interpretações, traremos alguns excertos que representam esses códigos, sejam dos objetivos, sejam dos resultados.

Esclarecemos a dinâmica adotada para as análises e interpretações realizadas: 1) uma forma vertical, isto é, trazendo os excertos dos objetivos e respectivos resultados de cada uma das comunicações analisadas e realizando as análises e interpretações em cada uma das diferentes tendências encontradas e 2) fazemos uma análise horizontal buscando uma perspectiva geral dos 15 trabalhos apresentados que buscaram relacionar as tendências, teorias e tecnologias com a Modelagem Matemática.

$\mathrm{O}$ código $(\mathrm{O} 1: 6)^{10}$ que representa "o objetivo com este artigo é discutir as ideias principais que irão nortear o desenvolvimento da investigação" e, (O1:23) "A pesquisa terá como objetivo principal a busca por subsídios para responder a pergunta diretriz, outro aspecto também poderá ser analisado" e (O1:38) "Tem por objetivo analisar como as Tecnologias de Informação (TIC) podem auxiliar estudantes a analisar fenômenos de seu interesse que sejam modelados matematicamente por Equações Diferenciais Ordinárias (EDOs) caracterizam dados empíricos que permitem identificar a categoria evidenciada". Os resultados associados a esta categoria podem ser visualizados nos dados a seguir: $\mathrm{O}$ código (R1:27 $7^{11}$ expressa " $\mathrm{A}$ primeira experiência, apesar de bastante inicial, mostrou-se promissora, devido ao envolvimento positivo por parte dos alunos no entendimento do fenômeno biológico apresentado e também do modelo matemático que o representa"; o código (R1:29) ao referirse sobre a investigação; "Esta devido à fase inicial em que a mesma se encontra não foram apontadas as questões relacionadas à metodologia, que ainda estão em fase inicial" e o código (R1:30) "Um estudo sobre a análise qualitativa na matemática também precisa ser desenvolvido".

Por ser um projeto piloto observa-se que os resultados ainda são incipientes, embora se proponha a discutir as ideias principais que irão nortear o desenvolvimento não o faz de forma

${ }^{10} \mathrm{O}$ código $\mathrm{O} 1: 6, \mathrm{O} 1: 22, \mathrm{O} 1: 23, \mathrm{O} 1: 38$ representam os códigos dos objetivos do artigo P1.

${ }^{11} \mathrm{O}$ código R 1:27, R1:29 e R1:30 representam os códigos dos resultados do artigo P1. 
razoável. Os resultados apresentados no artigo restringiram-se às considerações e intenções. Isso pode, em parte, ser explicado por ser uma investigação inicial, entretanto, as discussões sobre as ideias principais precisariam ocorrer uma vez que se propõe a tal empreitada. $\mathrm{O}$ emprego do verbo discutir, segundo Larocca, Rosso e Souza (2005), constitui um objetivo compreensivo e destaca ações destinadas a interpretar uma dada realidade, um problema mais amplo, e isso enseja a faculdade de perceber totalidades. Observa-se apenas nas considerações que o objetivo da investigação foi elaborar uma proposta de trabalho em que os estudantes do $1^{\circ}$ ano da graduação pudessem analisar de forma qualitativa fenômenos relacionados de seu interesse e que sejam modelados por Equações Diferenciais Ordinárias. Em suas considerações expressa "que a primeira experiência apesar de bastante inicial, mostrou-se promissora, devido ao envolvimento positivo por parte dos alunos no entendimento do fenômeno biológico apresentado e também do modelo matemático que o representa".

É importante que, nas considerações, sejam discutidos os aspectos apresentados como resultados, por isso, em uma experiência ou investigação são significativos entre alguns dados: as manifestações dos participantes, a realização, descrição e análise das atividades desenvolvidas, as manifestações espontâneas e entrevistas. Esses dados podem proporcionar elementos que evidenciem o envolvimento positivo dos participantes. Nesse sentido, os estudos de Bogdan e Biklen (1994) corroboram com essa afirmação, pois quando os dados em causa são produzidos por sujeitos, nesse caso em sala de aula, os investigadores querem saber como e em que circunstância é que eles foram elaborados. Assim a importância da participação em eventos dessa natureza é que, os espaços destinados às discussões das apresentações também podem se constituir, como um momento de reflexão para futuro encaminhamento ou redirecionamento de uma investigação ou de uma experiência.

No artigo P2, o código (O2: 30) que traz: “o objetivo do presente artigo é discutir a relação entre a Modelagem Matemática e a prática colaborativa na formação continuada de professores de matemática". Os resultados encontrados: "A Modelagem favorece que os alunos tenham uma relação mais afetiva com a disciplina de matemática" (R2: 19); "O interesse das professoras pela Modelagem foi determinante para inserção delas no grupo." (R2: 20); "Raquel busca ampliar seus conhecimentos em relação à Modelagem, e Flor busca melhorias em sua prática docente" (R2: 21); "Elas consideram que encontram no GCMM ${ }^{12} \mathrm{o}$ incentivo para o desenvolvimento de atividades de Modelagem em sua prática docente" (R2:22); "Para elas, as trocas de experiências realizadas no grupo são favorecidas pela relação de confiança existente entre os integrantes do grupo a saber: a prática colaborativa favorece que os professores superem dificuldades em suas atividades docente" (R 2:23); "A colaboração potencializa o desenvolvimento de projeto objetivado pelos professores" (R 2:24); "A partir do presente estudo, destacamos que a colaboração contribui para a inserção da Modelagem na prática dos professores" (R2:25); "Podem favorecer o desenvolvimento de práticas colaborativas para potencializar a inserção da Modelagem em sala de aula e que tais

${ }^{12}$ GCMM - Grupo Colaborativo em Modelagem Matemática. 
aspectos demandam ser discutidos nas pesquisas que buscam apoiar o professor no desenvolvimento de atividades de Modelagem" (R2:29).

Ao longo do texto, tenta-se discutir ações que embasam cada um dos resultados, entretanto em alguns deles não se aprofundam sobre as descrições da manifestação dos participantes. Por exemplo, qual situação ou situações de dificuldade(s) apresentada(s) pelo(s) participante(s) e, que envolveu a participação do GCMM se fez presente ou se fizeram presentes durante a realização do curso, a ponto de ensejar tal afirmação como em (R2:23).

Assim, é importante que as discussões, cujos objetivos almejam analisar, refletir e caracterizar, contemple elementos capazes de compreensão e interpretação de uma realidade, neste caso, a relação entre a Modelagem Matemática e a prática colaborativa na formação continuada de professores.

No artigo P5, o objetivo (O5:20) expressa "Neste artigo temos por objetivo evidenciar alguns aspectos que permitem uma aproximação entre a Modelagem Matemática e as Investigações Matemáticas". Os resultados apontados: "Este trabalho mostrou que a Investigação Matemática pode ser uma aliada no ensino do conteúdo matemático para fazer frente às questões levantadas numa atividade de Modelagem Matemática" (R5:18) e "mostra como uma preocupação para que outras investigações sobre essa temática sejam desenvolvidas, e não apenas em relação às Investigações Matemáticas, mas em relação a outras formas de abordar o conteúdo matemático" (R5:19). Os resultados manifestos encontram respaldo pela escassez de investigações que se propõem tematizar aproximações das "abordagens" e a Modelagem Matemática. $\mathrm{O}$ fato de ser aliada no ensino do conteúdo matemático refere-se à possibilidade de aproximar Investigações Matemáticas nos encaminhamentos das atividades de Modelagem em momentos em que este conteúdo, ainda não é conhecido pelos estudantes. Assim, realçam pontos que ajudam na compreensão da apresentação dos resultados. Esse é um tipo de trabalho recorrente na comunidade, ensaístico e, em certo sentido, exploratório. Apesar de sua importância e do espaço necessário a este tipo de trabalho, há que se incentivar a progressão deste tipo de abordagem e superar a realização de trabalhos pontuais.

No artigo P9 encontramos dois objetivos (O9:30) "Este trabalho tem como objetivo divulgar alguns pontos de uma pesquisa de mestrado que buscou analisar trabalhos de Modelagem Matemática na Educação à luz dos conceitos de prática educativa e ambiente de aprendizagem" e (O9:31) "Verificar se as diferentes denominações dadas à Modelagem levam a diferentes ações educativas". Os resultados associados aos objetivos são: "o agrupamento dos termos encontrados em três grandes blocos que seriam: 1) Estratégia; 2) Ferramenta; 3) Metodologia" (R9:2), "Concordamos que a utilização desses termos depende da experiência do leitor, de suas concepções e lócus onde está inserido.”(R9:26), “As ações educativas envolvidas na atividade de Modelagem praticamente não mudam. O que notamos é a mudança de motivos para sua aplicação e os atores que desenvolvem tais ações."(R9:27). Ainda, encontramos "A modelagem caracteriza-se como uma atividade que tem um motivo/necessidade para ser proposta e esse motivo/necessidade é buscada por meio de ações, com objetivos próprios, que são delegadas a diferentes atores individual ou coletivamente" 
(R9:28) e "Essa prática, então, constitui um ambiente de aprendizagem que busca dar importância às experiências dos estudantes e propicia novas experiências no processo de busca e produção do conhecimento" (R9:29). As justificativas para a formulação dos objetivos e dos resultados no artigo P9 encontram respaldo nas análises realizadas nos 57 artigos, que constituíram os Anais do V CNMEM.

Em relação aos resultados apresentados, alguns pontos podem ser colocados para discussão: ao buscar compreender a utilização dos diversos termos e expressões para denominar a Modelagem há de se considerar a existência de outras além das mencionadas, no entanto a discussão fulcral consiste em mostrar onde as práticas e as concepções distintas de Modelagem Matemática não divergem, isto é: o que se considera invariante nessas formas distintas de expressar a Modelagem Matemática? É ainda objeto desta compreensão o conhecimento em relação ao que diferem. Também há a necessidade de se ter maiores cuidados na apresentação dos resultados, pois, muitas vezes, não se leva em consideração o nível de ensino em que se situam a compreensão e o discurso do autor. Modelagem Matemática na Educação Matemática mostra-se, ainda, pouco compreendida, por exemplo, quando resultados fazem menção explícita de que não deve haver desvio de foco para outros aspectos, significando uma sinalização clara de não considerar outros aspectos que não os matemáticos na Modelagem Matemática. Ressalta-se a necessidade de realizar investigações mais rigorosas metodologicamente, de modo a contemplar uma revisão de literatura de outras concepções que apontam que a Modelagem Matemática na Educação Matemática não se restringe apenas à Matemática, mas no diálogo constante com outras áreas do conhecimento.

No artigo P10, encontramos como objetivo (O10:1) "Verificar quais são as concepções de Modelagem que poderemos ter quando da interação consciente dessa tendência com as Mídias Informáticas, no processo pedagógico". Os resultados decorrentes desse objetivo: “a modelagem no ensino é um processo que não depende exclusivamente do conhecimento matemático" (R10:19), também "A fragmentação do conhecimento torna difícil, de certa forma, a geração de respostas aos questionamentos da sociedade hodierna" (R10:20). Ainda encontramos "Que a Modelagem Matemática com recursos informáticos permite-nos novas dinâmicas no ensino de Matemática, precisamos fomentar, a partir desse novo contexto, outros olhares de mundo e de homem, buscando resgatar valores como o respeito ao meio em que vivemos e o respeito ao próximo, entendendo que qualquer ato contra o que e contra quem nos cerca é um ato contra nós próprio" (R10:21) e "Uma educação holística/contextualizadora pode acontecer a partir da prática individual, mas que precisa ser estimulada como prática coletiva, pois somente dessa forma é possível pensarmos em um mundo onde cada ser tenha a sua responsabilidade"(R10:22). As respostas ao objetivo proposto foram embasadas pela reflexão sobre os trabalhos de alguns autores, suas opiniões que alimentam suas perspectivas de Modelagem Matemática. A Modelagem Matemática na perspectiva do ensino e aprendizagem deve estabelecer o equilíbrio e articulação entre teoria e os recursos de outras tendências inseridas em sua prática. Deve, muitas vezes, ter o respaldo de dados empíricos que sustentam ou não uma teoria, se não se torna somente uma reflexão. É preciso avançar sim, mas em que direção? A do discurso? A da prática ou à direção do 
discurso e prática que realmente levem em conta o sujeito da aprendizagem? Esses aspectos enfraquecem e fragiliza a pesquisa e consequentemente a prática em relação à Modelagem Matemática na Educação Matemática, pois como aponta Geertz (1973 apud BOGDAN; BIKLEN, 1994, p. 49)

Se a interpretação de cunho mais antropológico consiste na leitura dos acontecimentos, então divorciá-la do que se passa-daquilo que, em determinado momento espaço-temporal pessoas afirmam ou fazem ou sofrem, é o mesmo que divorciá-la das suas aplicações, tornando-a oca.

No artigo P15, temos dois objetivos explicitados: "Apresentar considerações iniciais sobre um curso de formação continuada em Modelagem Matemática oferecido na modalidade de Educação a Distância, mediado pelas TICs, mais especificamente a Internet" (O15:11), "Interpretar, à luz da pesquisa qualitativa, se as interações possibilitadas pelas ferramentas da modalidade da EaD contribuem para a superação das dificuldades do professor em utilizar a MM na sala de aula" (O15:12). Os resultados decorrentes desses objetivos estão expressos por: "As ferramentas da Plataforma Moodle se mostram eficientes e adequadas para os propósitos desta fase do curso, atendendo às expectativas, pois as várias formas de interação, proporcionadas pelo fórum, chat, e diário, revelam uma interação forte entre os participantes" (R.15:47); ainda, " A atividade Wiki cria uma forma de interação colaborativa entre alunos e professor, permitindo a construção coletiva de uma determinada informação" (R15:49), "As conclusões finais serão feitas após a reunião de todos os dados coletados na Plataforma Moodle e do grupo focal, que será realizado presencialmente com todos os professores (R15:52); e "As conclusões finais serão feitas após reunião de todos os dados coletados na Plataforma Moodle e do grupo focal, que será realizado presencialmente com todos os professores" ( R15:53).

Ao buscar elementos que justifiquem que as ferramentas da plataforma Moodle foram adequadas aos propósitos do curso, uma vez que pelas manifestações presentes nas ferramentas disponíveis, o autor percebeu e manifestou as angústias e frustrações dos participantes em relação ao ensino e aprendizagem, assim como a expectativa de melhorias no trabalho com a MM em suas turmas decorrente da realização do curso. Justifica ainda, a importância de coletar dados e utilizá-los como subsídios para a elaboração das fases práticas das atividades de MM.

Em relação à ferramenta Wiki, manifesta a necessidade de que ocorra a participação colaborativa de cada participante do grupo, pois na medida em que intervém no processo, torna-se coautor do conhecimento produzido. Traz ainda, como embasamento, o trabalho de Borba et. al. (2008) em que recomenda que além da colaboração dois outros fatores são importantes: a interação e o diálogo, uma vez que a qualidade da Educação a Distância está diretamente relacionada a eles.

Nos elementos das manifestações dos professores participantes do curso com o propósito de avaliar a adequação das ferramentas do Moodle, o pesquisador percebeu e manifestou as angustias e frustrações dos participantes em relação ao ensino e a aprendizagem, assim como a expectativa de melhorias no trabalho com a Modelagem Matemática em suas turmas 
decorrentes da realização do curso. Entretanto, a ausência explícita dos conteúdos dessas manifestações capturadas pelas diversas ferramentas do Moodle, evidencia a necessidade de trazer elementos das manifestações expressas dos participantes, presentes nas ferramentas fórum, wiki, chats e grupo focal como forma de legitimar as considerações. Assim, que fragmentos contidos nas diversas ferramentas ensejaram as percepções de angustias e frustrações dos participantes? Os resultados carecem trazer elementos de convencimento que legitimem as considerações feitas.

Em P27, o objetivo eleito foi: "Neste trabalho busca-se incentivar a introdução de novas metodologias estatísticas no ensino médio, especificamente do coeficiente de correlação de Spearman" (O27: 4). Os resultados expressos são: "O coeficiente de correlação de Spearman, conhecido como coeficiente de correlação de postos pode ser utilizado no ensino médio, como um elemento de aprendizado dentro do tema análise combinatória" (R27:2), "O cálculo desse coeficiente é simples, de fácil entendimento e as permutações necessárias para a obtenção da distribuição nula podem ser obtidas sem grandes esforços" (R27:3), também "Discussões Temáticas, com abordagem de temas sociais nas aulas de matemática podem ser úteis para a transformação social que se busca na formação de cidadãos que tenham interesses e conhecimentos variados" (R27:5) .

O artigo refere-se à adoção da Educação Estatística no Ensino Médio. Alguns dos resultados são justificados pelos exemplos em que o coeficiente de correlação pode ser utilizado. E normalmente envolve temas como IDH, o preço de determinados produtos e o número de famílias possuidoras daquele tipo de produto; entre a altura e peso dos estudantes. Traz exemplos envolvendo temas sociais.

No entanto, apresenta e desenvolve os exemplos sem a preocupação de estabelecer relações mais específicas com o Ensino Médio. Tendo em vista que menciona uma intencionalidade de inserção da Educação Estatística no âmbito do Ensino Médio peca, por não realizar uma articulação mais consistente. Fica apenas no intento. Não explicita no artigo se a proposta teve envolvimento de estudantes deste nível de ensino, pois não apresenta maiores detalhes. $\mathrm{O}$ desígnio dessa inserção no Ensino Médio parece dizer respeito unicamente à simplicidade e à facilidade de obtenção dos coeficientes utilizados nas situações que envolvem alguns temas sociais.

\section{Sintetizando e avançando em relação ao exposto}

Considerando o material analisado, que levou em conta apenas uma categoria dos objetivos e tendo o respaldo nos elementos manifestos pelos resultados nos artigos analisados, podemos afirmar que a VI Conferência Nacional de Modelagem na Educação Matemática apresentou avanços para o campo da Modelagem Matemática, notadamente no intento de buscar associar a Modelagem Matemática a outras teorias, tendências ou tecnologias. Dos 31 trabalhos apresentados 15 buscaram essa associação. 
Embora, esse avanço não se perpetre com base nos resultados mais expressivos da pesquisa, pois, na maioria das vezes, estes se apresentam momentaneamente desarticulados em relação aos objetivos, com alusões frágeis referindo-se predominantemente sobre o aspecto pedagógico, ou mesmo sobre a tendência em pauta do que, propriamente no estabelecimento de articulações decorrentes de pesquisa mais consistente e rigorosa sobre o ensino, a aprendizagem e o conhecimento novo que, em nosso entendimento, podem possibilitar avanços rumo à consolidação do campo da Modelagem no âmbito da Educação Matemática.

Em muitas ocasiões, de um lado, se enfatiza a teoria que busca relacionar-se com a Modelagem Matemática, dando a ela maior destaque, ou de outro lado, ressalta a Modelagem Matemática sem promover articulações mais significativas com a teoria que tenta relacionar. Considerando que a cada evento observa-se a presença de novos participantes, sejam estudantes da graduação ou da pós-graduação, além de professores da Educação Básica, as compreensões teóricas são distintas, as vivências em campo também são diferenciadas. Assim, é plausível compreender essa falta de articulação, pois, ainda, a grande preocupação centra-se em comprovar a teoria em relação à Modelagem. Outras ainda são devidas ao pouco tempo dedicado às experiências, envolvendo as atividades de Modelagem. Qualquer experiência necessita de um tempo mais amplo para a análise do material, das produções dos envolvidos, das manifestações dos participantes, das teorias envolvidas e em especial para reflexões sobre o vivido. Um aspecto a ser considerado diz respeito à falta de reflexão epistemológica que torna capaz de ensejar resultados desarticulados, pouco claros e de mínima contribuição para a consolidação da Modelagem na Educação Matemática. Ressaltese à necessidade de realizar investigações mais rigorosas metodologicamente e mais coerentes sob o ponto de vista epistemológico.

Por um lado essa desarticulação e a falta de maior reflexão sobre a Modelagem na Educação Matemática e associação com as teorias, tendências ou tecnologias no âmbito da pesquisa são parte de um processo educativo, pois além dos novos participantes da comunidade da Modelagem muitos são oriundos de formações distintas, de atuações em níveis de ensino distintos, mas que pela sensibilidade e opção buscam a Modelagem na Educação Matemática e encontram-se, desse modo, em meio a um processo de compreensão da nova área de estudos. De outro lado, em relação ao campo da Modelagem na Educação Matemática como área de investigação permite mostrar ser impossível um crescimento, uma evolução sem que se admitam suas fragilidades e suas deficiências.

O campo da Modelagem na Educação Matemática comporta, para além da investigação, as decorrências que envolvem a Educação e as áreas que lhe dão sustentação e a Matemática. Esse chamado novo campo de estudos - Modelagem na Educação Matemática aponta nitidamente à necessidade de ruptura de um único modelo, como forma suprema de reconhecimento de conhecimento de interpretação da realidade. Essa afirmação encontra respaldo em Kuhn (1987), quando afirma a importância da construção e reconstrução no conhecimento científico a partir das rupturas no processo de construção do conhecimento. Essas descontinuidades e revoluções é que permitem a passagem qualitativa de um paradigma a outro. As mudanças paradigmáticas têm profunda penetração no campo das ciências, pois 
encerram e inauguram novos saberes. Essa forma de pensamento também está legitimada nos estudos de Santos (2006). Nesses estudos Santos (2006, p. 14), afirma: “os grandes cientistas que estabeleceram e mapearam o campo teórico em que ainda hoje nos movemos viveram ou trabalharam entre o século XVIII e os primeiros vinte anos do século XX". O autor, ainda complementa que, em termos científicos, vivemos ainda no século XIX e que o século XX ainda não começou e adverte que, talvez nem comece antes de terminar. Para Santos (2006) seus estudos mostram que são hoje muitos e fortes os sinais de que o modelo de racionalidade científica em alguns de seus traços principais atravessa profunda crise e, defende ainda, que

Essa crise é não só profunda como irreversível e segundo que estamos a viver um
período de revolução científica que se iniciou com Einstein e a mecânica quântica
[...] e que os sinais nos permitem tão só especular acerca do paradigma que emergirá
deste período revolucionário, mas que, desde já afirmar com segurança que
colapsarão as distinções básicas em que se assenta o paradigma dominante
(SANTOS, 2006, p. 40-41).

Dessa forma, afirmamos que esse novo campo de estudos, a Modelagem na Educação Matemática, também se constitui uma espécie de crise na forma de se pesquisar e suas implicações para novos conhecimentos e para a prática escolar. A pesquisa numa perspectiva da meta-análise permite ao pesquisador chegar a outros olhares e elementos de consideração. Para Larocca et. al. (2005) a abordagem meta-analítica caracteriza-se como um tipo de pesquisa avaliação que permite ponderar de forma crítica o que vem sendo produzido cientificamente, identificando entraves e deficiências possibilitando formas mais apropriadas de produção.

Assim, as ausências bem como os elementos presentes observadas nos trabalhos levam à necessidade de se compreender o processo de construção do conhecimento. O entendimento dessa compreensão é o objetivo da epistemologia da ciência. É segundo Japiassu (1991, p.16) "o estudo metódico e reflexivo do saber, de sua organização, de sua formação, de seu desenvolvimento, de seu funcionamento e de seus produtos intelectuais”. Seu principal objetivo é estudar o processo de se fazer ciência, neste caso a pesquisa em Modelagem na Educação Matemática que está em devir.

Portanto, não se constituem em preocupação apenas as ausências dos objetivos percebidas em trabalhos, mas a acepção dada aos objetivos presentes e as implicações nos resultados. A variedade e a amplitude dos objetivos principalmente da categoria objetivos-meio, conforme Larocca et. al. (2005, p. 127), em que são muito variadas, torna-se difícil detectar os reais propósitos do autor ou autores dos trabalhos e ainda, indagando "sobre as possibilidades de o objetivo dar respostas para a problematização posta é possível perceber uma diferença entre a intenção de atingir respostas para as problematizações da intenção de construir meios para alcançá-las".

Esses aspectos incidem diretamente sobre a pesquisa, como falta de clareza metodológica e quando mesmo aqueles que se colocam na categoria de objetivos propositivos ou compreensivos a ausência de uma maior compreensão metodológica produz resultados frágeis e desconexos. 
Dessa forma, volver esforços para compreender esse novo campo de estudos significa debruçar-se sobre a compreensão dos fundamentos que constituem as áreas que dão sustentação à Educação Matemática respeitando-se sua natureza e metodologia e distinguir com clareza seu objeto de estudo. A pequena atenção dada a esses aspectos da Educação Matemática constituem grande parte dessa fragilidade e deficiência na produção intelectual sobre a Modelagem. Essas constatações somente podem ser ultrapassadas pela ruptura com o paradigma predominante no ensino de Matemática e na concepção de Modelagem Matemática, ainda vigente na maior parte da produção que envolve a Modelagem na Educação Matemática. É com essa convicção que se espera conseguir a consolidação do campo da Modelagem na Educação Matemática.

\section{Referências}

ALMEIDA, L. M. W. de. Algumas reflexões sobre a pesquisa em Modelagem Matemática. In: SEMINÁRIO INTERNACIONAL DE PESQUISA EM EDUCAÇÃO MATEMÁTICA, 3., 2006, Águas de Lindóia. Anais... Curitiba: SBEM, 2006, p. 1-12.

VERTUAN, R.E.; KLUBER, T. E. Relatório Científico do V SIPEM: GT -10 Modelagem Matemática. Boletim Temático: Divulgação do relatório do $\mathrm{V}$ Seminário Internacional de Pesquisa em Educação Matemática, Petrópolis, n.19, p. 13-15, 2012.

ARAÚJO, J. L. Pesquisas sobre Modelagem em eventos científicos recentes de educação matemática no Brasil. In: SEMINÁRIO INTERNACIONAL DE PESQUISA EM EDUCAÇÃO MATEMÁTICA, 4., 2009, Taguatinga. Anais ... Taguatinga: UCB, 2009, p. 114.

BARBOSA, J. C. Sobre a pesquisa em modelagem matemática no Brasil. In: CONFERÊNCIA NACIONAL SOBRE MODELAGEM NA EDUCAÇÃO MATEMÁTICA, 5., 2007, Ouro Preto. Anais... Ouro Preto: UFOP / UFMG, 2007, p. 82-103.

BARDIN, L. Análise do conteúdo. Tradução de Luis Antero Reto e Augusto Pinheiro. Lisboa: Edições 70, 2009.

BICUDO, M. A. V.; KLÜBER, T. E. Pesquisa em modelagem matemática no Brasil: a caminho de uma metacompreensão. Cadernos de Pesquisa, São Paulo, v.41, n.144, p.902925, set. / dez. 2011.

BOGDAN, R.; BIKLEN, S.K. Investigação qualitativa em educação: uma introdução à teoria e aos métodos. Tradução de Maria João Alvarez, Sara Bahia dos Santos e Telmo Mourinho Baptista. Portugal: Porto Editora, 1994.

BORBA, M. C.; MALHEIROS, A.P.S.; ZULATTO, R.B.A. Educação a Distância online. Belo Horizonte: Editora Autêntica, 2008.

BURAK, D. et al. Sobre os objetivos de pesquisa concernentes à investigação em modelagem matemática na educação matemática. In: SEMINÁRIO INTERNACIONAL DE PESQUISA 
EM EdUCAÇÃo MATEMÁTICA, 5., 2012, Petrópolis. Anais... Petrópolis: SIPEM, 2012, p.1-18.

JAPIASSU, H.. Introdução ao Pensamento Epistemológico. 6 ed. São Paulo: Francisco Alves, 1991.

KLÜBER, T.E.. Uma metacompreensão da Modelagem Matemática na Educação Matemática. 2012. 396 f. Tese (Doutorado em Educação Científica e Tecnológica) - Centro de Ciências Físicas e Matemática, Universidade Federal de Santa Catarina, Florianópolis, 2012.

KLÜBER, T. E.; BURAK, D . Sobre a pesquisa qualitativa na Modelagem Matemática em Educação Matemática. Bolema: Boletim de Educação Matemática, v.26, n. 42, p. 111-133, 2012a.

- Sobre os objetivos, objetos e problemas da pesquisa brasileira em Modelagem Matemática na Educação Matemática. Revista Práxis Educativa, v. 7, n. 2, p. 467-488, $\mathrm{jul} / \mathrm{dez} 2012 \mathrm{~b}$.

KUHN, T.S. A estrutura das revoluções científicas. 2ed. São Paulo: Editora Perspectiva, 1987.

LAROCCA, P.; ROSSO, A.J.; SOUZA, A.P. A formulação de objetivos de pesquisa na pósgraduação em Educação: uma discussão necessária. Revista Brasileira de Pós-Graduação RBPG, v.2, n.3, p. 118-133, 2005.

NISS, M.. Issues and problems of research on the teaching and learning of applications and modelling. In: MATOS, J. F.; BLUM, W.; HOUSTON, S. K. Houston.; CARREIRA, S. P. Modelling and mathematics education - ICTMA 9: Applications in science and technology. Chichester: Horwood Publishing, 2001, p. 72-88.

SANTOS, B. de S. Um discurso sobre as ciências .4.ed. São Paulo: Editora Cortez, 2006.

WALTER, S. A.; BACH, T. M. Adeus papel, marca-textos, tesoura e cola: Inovando o processo de análise de conteúdo por meio do Atlas. In: SEMINÁRIOS DE EMPREENDEDORISMO E EDUCAÇÃO, 12., 2009, São Paulo. Anais... São Paulo, USP: 2009, p.1-17.

Material analisado: Comunicações Científicas da VI Conferência Nacional sobre Modelagem na Educação Matemática - 2009. 